\title{
Psychiatric co-morbidity in chronic migraine Patients: A hospital based study
}

\author{
Gupta U1, Aich TK², Verma AK ${ }^{3}$ \\ 1. Asst. Prof., Department of psychiatry, UCMS, Bhairahawa, Nepal 2. Professor, Department of psychiatry, \\ UCMS, Bhairahawa, Nepal 3. Asst. Prof. JMC, Janakpur, Nepal
}

Email Corresponding Author: uttamgupta68@yahoo.com

\section{Abstract}

Aim and Objectives: To study the socio-demographic and clinical profile of patients with chronic migraine headache, and to study the frequency and pattern of co-morbid psychiatric illnesses amongst these patients.

Methodology: The study was done at the headache clinic in the Department of Psychiatry at Universal College of Medical Sciences, Bhairahawa, Nepal. All out-patients attending our clinic over a period of three months and aged between 15 to 55 years with a diagnosis of chronic migraine headache were included in the present study. Demographic and clinical profiles of these patients were noted in a specially designed socio-demographic and clinical data sheets prepared for the present study. Schedules for Clinical Assessment in Neuropsychiatry (SCAN) was used as diagnostic instrument; Hamilton Rating Scales for Anxiety \& Depression (HAM-A, HAM-D) were used to rate the severity of Anxiety and Depressive symptoms. Simple statistical procedures like frequency, percentages, ' $t$ '-tests and chi-square tests were used for analysis of data thus obtained.

Results: A total no of 48 cases of chronic migraine were included in the present study. Forty one cases (85.4\%) were female and rest 7 patients were male. Comorbid psychiatric illness was present in thirty one (64.6\%) cases among which Anxiety was the most common diagnosis (35.4\%) followed by depressive disorders $(29.2 \%)$.

Conclusion: chronic migraine headache has high rate of co-morbid mood and anxiety disorder. Effective treatment of chronic migraine headache requires screening and accurately diagnosing specific psychiatric disorders when present.

Keywords: Migraine Headache, Comorbidity, Depression, Anxiety.

\section{INTRODUCTION}

Headache is a symptom which can be defined as pain occurring as a result of stimulation of intracranial and extra cranial tissues due to varying reasons.1,2 Primary headache includes Migraine Headache, Tension Type Headache, Cluster Headache etc. Migraine is a chronic neurological disorder characterized by episodic attacks of headache and associated symptoms. In western countries, the condition affects $12 \%$ of the adult population. ${ }^{3}$ Types of migraine ${ }^{4-6}$ described in the literature are Migraine without aura, Migraine with aura, Childhood periodic syndromes that are commonly precursors of migraine, Retinal migraine, Complications of migraine, etc.

Migraine headache has at least two of the following characteristics 7,8 : unilateral location, pulsating quality, moderate or severe pain intensity, aggravation by or causing avoidance of routine physical activity (i.e. walking or climbing stairs). During headache at least one of the following symptoms must be present: Nausea and/or vomiting, Photophobia and phonophobia.

Chronic daily headache is defined as headache without underlying lesions and without symptoms of disease that might be causing this chronic headache, occurring on more than 15 days a month for more than 3 months and lasting for more than 4 hours per day if untreated. Chronic migraine (CM) is the most common of the chronic daily headaches, and also includes chronic tension-type headache, hemicranias continua, and new daily persistent headache. ${ }^{9}$ 
There is strong evidence that migraine is co-morbid with a number of different conditions. These are Epilepsy, Stroke, Depression, Anxiety disorders and Manic depressive illness. There is less strong evidence that migraine is also associated with Mitral valve prolapse and Reynaud's syndrome. ${ }^{10}$

Only few studies are reported on migraine headache from Nepal till date, which prompted us to go for the present study. Aim was to study the socio-demographic and clinical profile of patient diagnosed as chronic migraine headache and to study the frequency and pattern of psychiatric comorbid illnesses amongst them.

\section{METHODS}

The study was carried out at the headache clinic in the Department of Psychiatry at Universal College of Medical Sciences (UCMS), Bhairahawa, Nepal. It was a descriptive study for which a purposive sampling was taken. Study sample consisted of all the cases that attended in our headache clinic for the first time over a period of 3 months. Inclusion criteria were the subjects fulfilling the diagnosis of "Primary Chronic Migraine Headache" aged between 15 to 55 years and having given informed consent for the study. Following tools were used for the study:

Socio-demographic and clinical data sheet: A semi-structured proforma was especially drafted, which contained all the socio-demographic and clinical details of the patient relevant to the study. Socio-demographic variables included age, sex, education, family background, etc. Clinical variables included presenting complain, mode of onset, course of illness, duration of illness, frequency of headache, presence of aura, location, intensity, quality, type and radiation of headache, aggravating and relieving factors etc.).

International Headache Society guidelines for classification and diagnosis of headache (ICHD2) ${ }^{7}$ : Headache cases were diagnosed according to IHS criteria, 2004.

SCAN (Schedules for clinical Assessment in Neuropsychiatry) (1996) ${ }^{11}$ : SCAN system had been developed in the frame work of World Health Organisation (WHO) and National Institute of Health (NIH) joint project on Diagnosis and Classification of Mental disorders, Alcohol and Drug Related Problems.

SCAN version 2.1 published in 1996 represents the development in standardized psychiatric assessment and diagnosis. SCAN is a set of instruments aimed at assessing, measuring and classifying the psychology and behaviour associated with major psychiatric syndromes of adult life. It has four components; the tenth edition of the Present State Examination (PSE-10), the Glossary of differential Definitions, the Item Group Check list (IGC), and the Clinical History Schedule (CHS). PSE-10 itself has two parts, part one covers somatoform disorder, dissociative, anxiety, depressive and bipolar disorders, and problem associated with basic bodily functions and use of alcohol and other substances. There is also a screen for two conditions. Part two covers psychotic and cognitive disorders and observed abnormalities of speech, affect and behaviour.

International classification of mental and behavior disorder $1^{\text {th }}$ Edition (ICD-10): Psychiatric COmorbidity was established according to ICD-10. ${ }^{12}$

Hamilton rating scale for anxiety and depression was used to assess the severity of co-morbid anxiety and depression. Hamilton Rating Scale for Anxiety (HAM-A) ${ }^{13}$ was developed by M Hamilton in 1959, is the most widely utilized assessment scale for anxiety symptoms, and was originally intended to be used to evaluate individuals who are already diagnosed with anxiety disorders. It consist of 14 items, each item was rated from 0 to 4 severity rating scale $(0=$ not present, $4=$ severe $)$. Hamilton Rating Scale for Depression (HAM-D) ${ }^{14}$ was developed by M Hamilton in 1960, is the most widely utilized rating scale to assess severity of depression in patients already diagnosed with a depressive disorder. The HAM-D is an observer rated scale contains 21 ratings measured on three $(0$ to 2 ) or five (0 to 4$)$ point scales. The first 17 items are used in scoring the instrument, whereas the final four items provide more detail on the clinical characteristics of the depression. Themes that are difficult to quantify are rated grossly on a 0 to 2 scale: $0=$ symptom absent, $1=$ slight or doubtful, and 2 = clearly present. Other items are graded more finely on a 0 to 4 scale in terms of increasing intensity: $0=$ symptom absent, $1=$ doubtful or trivial, $2=$ mild, $3=$ moderate and $4=$ severe.

ASSESSMENT PROCEDURE: All the new cases registered at the Headache clinic were taken up for initial screening for the purpose of the present study. During the study period (approx. a period of 3 months) a total of 486 patients attended our headache clinic. Amongst them 136 of them were registered for the first time. A detail assessment of all these new cases was done in the beginning. A 
total of 48 cases were finally taken up after applying the inclusion and exclusion criteria set for the present study.

All these 48 cases worked-up in detail and diagnosis of chronic migraine headache was made according to IHS criteria 2004 (ICHD-II). Sociodemographic and clinical data received from these patients were filled in a proforma specially designed for the present study. Each of the selected cases were then administered SCAN (version 2.1) to collect information about any mental or behavioural symptoms present in the cases at the time of study. Each SCAN interview took approximately 45 minutes to 60 minutes. Necessary obligatory training was obtained regarding use of SCAN from co-author (TKA), who had prior training in using SCAN as a rating scale.

The data thus received was recorded on SCAN CODING BOOKLETS according to rating scales fixed in each section. SCAN glossary was used to settle any ambiguity regarding differential definitions, symptoms and ratings. The data thus received was then verified according to ICD-10 to confirm the presence or absence of psychiatric diagnosis and the precise diagnosis, wherever present. Finally, all the cases thus assessed were discussed with the consultant-in-charge of the headache clinic. Final diagnosis of headache was noted and co-morbid psychiatric diagnosis was also confirmed after detail discussion with the psychiatrist-in-charge of the headache clinic.

Once psychiatric co-morbidity was established, Hamilton Rating Scale for Anxiety (HAM-A) and Hamilton Rating Scale for Depression (HAM-D) were used to assess the severity of anxiety and depression in those patients with presence of comorbid anxiety and depression.

STATISTICAL ANALYSIS: All data thus obtained during interview and noted on socio-demographic and clinical data sheets and rated on HAM-A and HAM-D were entered into SPSS-14 version programme. Percentage profile of different clinical and socio-demographic variables among different groups and sub-groups was calculated and described. 'Chi-square' test with Yate's correction, whenever appropriate, was done to categorical data and ' $t$ '-test was applied for the continuous data, thus obtained.

\section{RESULTS}

A total of 48 patients (41 female; 7 male) of chronic migraine headache were taken up for the present study. Demographic distribution of these patients is presented in table no 1 . Mean age of our patient population was 30.27 years with $89 \%$ (38) of them belonged to age group of 15-35 years. Thirty five subjects $(72.9 \%)$ were literate and the rest $13(27.1 \%)$ were illiterate. Thirty eight $(79.2 \%)$ patients came from rural background whereas the rest $10(20.8 \%)$ came from urban area. When we tried to assess regional distribution of these patients we found that $60.4 \%$ (29) of them were from Terai-belt and the rest $39.6 \%$ (19) came from hilly region. Forty $(83.3 \%)$ subjects came from joint family whereas the rest 8 $(16.7 \%)$ were from nuclear family setup.

Table 1: Demographic Profile of Patients

\begin{tabular}{|c|c|}
\hline Age (in years) & $30.27(\mathrm{SD}=7.75)$ \\
\hline \multicolumn{2}{|l|}{ Age in groups } \\
\hline $15-25$ & $17(35.4 \%)$ \\
\hline $26-35$ & $21(43.8 \%)$ \\
\hline $36-45$ & $10(20 \%)$ \\
\hline \multicolumn{2}{|l|}{ Sex } \\
\hline Male & $7(14.6 \%)$ \\
\hline Female & $41(85.4 \%)$ \\
\hline \multicolumn{2}{|l|}{ Education } \\
\hline Literate & $35(72.9 \%)$ \\
\hline Illiterate & $13(27.1 \%)$ \\
\hline \multicolumn{2}{|l|}{ Marital status } \\
\hline Married & $37(77.1 \%)$ \\
\hline Unmarried & $11(22.9 \%)$ \\
\hline \multicolumn{2}{|l|}{ Residence } \\
\hline Rural & $38(79.2 \%)$ \\
\hline Urban & $10(20.8 \%)$ \\
\hline \multicolumn{2}{|l|}{ Region } \\
\hline Tarai & $19(39.6 \%)$ \\
\hline Hills & $29(60.4 \%)$ \\
\hline \multicolumn{2}{|l|}{ Family types } \\
\hline Nuclear & $8(16.7 \%)$ \\
\hline Joint & $40(83.3 \%)$ \\
\hline
\end{tabular}


Clinical profiles of these patients were presented in table no 2. Mean duration of migraine headache was 20.1 months $(\mathrm{SD}=24.4)$. Sub classifying migraine headache further we got migraine with aura in $34(71 \%)$ cases and rest $14(29 \%)$ cases as migraine headache without aura. When we tried to see the pattern of localization of headache at onset, we found that headache started maximally over temporal region in $54.2 \%$ (26) cases.

Table 2: Clinical Profile of patients with Migraine

\begin{tabular}{|l|l|}
\hline Variables & N (\%) \\
\hline Duration (months) & $20.1 \mathrm{SD}=24.4$ \\
\hline Frequency of headache & \\
Multiple in weak & $33(68.8 \%)$ \\
Daily & $15(31.2 \%)$ \\
\hline Intensity & $1(2.1 \%)$ \\
Mild & $8(16.7 \%)$ \\
Moderate & $28(58.3 \%)$ \\
Severe & $11(22.9 \%)$ \\
Incapacitating & \\
\hline Location & $20(41.7 \%)$ \\
Frontal & $2(4.2 \%)$ \\
Central & $26(54.2 \%)$ \\
Temporal & \\
\hline Precipitant & $5(10.4 \%)$ \\
Absent & $43(89.6 \%)$ \\
Present & \\
\hline Diagnosis & $14(29.2 \%)$ \\
Migraine without aura & $34(70.8 \%)$ \\
Migraine with aura & \\
\hline Co-morbidity & $14(29.2 \%)$ \\
Absent & $17(35.4 \%)$ \\
Anxiety & $14(29.2 \%)$ \\
Depression & $3(6.2 \%)$ \\
Panic & \\
\hline HAM-A & $23(47.9 \%)$ \\
Absent & $2(4.2 \%)$ \\
Mild & $14(29.2 \%)$ \\
Moderate & $9(18.8 \%)$ \\
Severe & \\
\hline HAM-D & $20(41.7 \%)$ \\
Absent & $15(31.2 \%)$ \\
Mild & $11(22.9 \%)$ \\
Moderate & $2(4.2 \%)$ \\
Severe & \\
\hline & \\
\hline
\end{tabular}

Assessing the severity of intensity of migraine headache we found milder headache in $2.1 \%$ (1) cases, moderate headache in $16.7 \%$ (8) cases and severe intensity headache in $58.3 \%$ (28) cases and incapacitating headache in $22.9 \%$ (11) patients. Distinct precipitating/aggravating factors for migraine were found to be present in $89.6 \%$ (43) cases. Psychiatric co-morbidity was present in $70.8 \%$ (34) subjects. Anxiety was the most common co-morbidity found (35.4\%), followed by Depressive disorder (29.2\%) and Panic disorder $(6.2 \%)$.

Table no.3 reveals that there was no significant difference between Migraine with aura and Migraine without aura on several demographic parameters. Patients from Hilly region had more number of migraine with aura than patients coming from Terai region $\left(x^{2}=12.56, p=0.001\right)$, literate patients had more number of migraine with aura than illiterates $\left(x^{2}=5.2, p=0.02\right)$ and Nepali speaking patients reported more number of migraine with aura than Hindi speaking patients $\left(x^{2}=9.7, p=0.005\right)$.

Table 3: Diagnosis And Demographic Variables Compared.

\begin{tabular}{|c|c|c|c|c|}
\hline VARIABLE & $\begin{array}{l}\text { Migraine } \\
\text { without } \\
\text { aura }\end{array}$ & $\begin{array}{l}\text { Migraine } \\
\text { with } \\
\text { aura }\end{array}$ & $\mathrm{X} 2 / \mathrm{t}$ & p \\
\hline $\begin{array}{l}\text { Age groups } \\
15-25 \\
26-35 \\
36-45\end{array}$ & $\begin{array}{l}8 \\
4 \\
2\end{array}$ & $\begin{array}{l}9 \\
17 \\
8\end{array}$ & 4.08 & 13 \\
\hline $\begin{array}{l}\text { Sex } \\
\text { Male } \\
\text { Female }\end{array}$ & $\begin{array}{l}1 \\
13\end{array}$ & $\begin{array}{l}6 \\
28\end{array}$ & 87 & 3 \\
\hline $\begin{array}{l}\text { Education } \\
\text { Literate } \\
\text { Illiterate }\end{array}$ & $\begin{array}{l}7 \\
7\end{array}$ & $\begin{array}{l}28 \\
6\end{array}$ & 5.2 & $.02^{* *}$ \\
\hline $\begin{array}{l}\text { Marital } \\
\text { status } \\
\text { Married } \\
\text { Unmarried }\end{array}$ & $\begin{array}{l}10 \\
4\end{array}$ & $\begin{array}{l}19 \\
27\end{array}$ & 35 & 40 \\
\hline $\begin{array}{l}\text { Residence } \\
\text { Rural } \\
\text { Urban } \\
\end{array}$ & $\begin{array}{l}13 \\
1\end{array}$ & $\begin{array}{l}25 \\
9 \\
\end{array}$ & 2.24 & 13 \\
\hline $\begin{array}{l}\text { Region } \\
\text { Terai } \\
\text { Hills }\end{array}$ & $\begin{array}{l}11 \\
3\end{array}$ & $\begin{array}{l}8 \\
26\end{array}$ & 12.56 & $0.001^{* *}$ \\
\hline $\begin{array}{l}\text { Family } \\
\text { Nuclear } \\
\text { Joint }\end{array}$ & $\begin{array}{l}2 \\
12 \\
\end{array}$ & $\begin{array}{l}6 \\
26 \\
\end{array}$ & .081. & .57 \\
\hline $\begin{array}{l}\text { Language } \\
\text { Nepali } \\
\text { Hindi }\end{array}$ & $\begin{array}{l}8 \\
6\end{array}$ & $\begin{array}{l}32 \\
2\end{array}$ & 9.7 & $0.005^{* *}$ \\
\hline
\end{tabular}

*Significant at 0.05 level, ${ }^{* *}$ Significant at 0.01 level, *** Significant at 0.001 level 


\section{DISCUSSION:}

Out of a total of 48 patients 41 patients were female (85.4\%). Mitsikostas and Thomas ${ }^{15}$ also reported that $70 \%$ of their migraine sufferers were female and rest $30 \%$ patients were male. Similar results were also reported by Jung et al. ${ }^{16}$

Mean age of our patient population was 30.27 years with $89 \%$ (38) of them belonged to age group of 15 35 years. Mercante et al in their study on chronic migraine reported a mean age 36.3 years in their patient population. ${ }^{17}$ Wang et al., in a study on chronic daily headache in adolescents reported a mean age of 21.6 years. ${ }^{18}$

Migraine with aura present in $29.2 \%$ cases and migraine without aura present in $29.8 \%$ of our migraine headache patients. Seilberstein et al., (1996) reported migraine with aura in $21.5 \%$ their headache cases and migraine without aura in $78.5 \%$ of their migraine cases. ${ }^{9}$ The study by Mitsikosta et al. reported Migraine with aura in 8\% (38), Migraine without aura in $28 \%$ (132), of their chronic daily headache cases. ${ }^{15}$

Various physical and psychological factors are known to precipitate and/or aggravate headaches. Some of our patients who reside in Terai region experienced headache as soon as they reached the Hilly terrain in Nepal (headache following change in barometric pressure).

One female patient reported increase frequency of migraine headache during menstruation periods (menstrual migraine). One male patient reported increase frequency of migraine headache just after sexual activity (post-coital headache).

Food items like chocolates, coffee had increased frequency of headache in some of our study population. Few patients also reported an increase in migraine headache after getting exposed to different types of odors.

Change in sleep habits, chewing, coughing and sneezing etc., was also noted as precipitating/aggravating factors in some patients. Few other patients reported headache precipitation/aggravation following exposure to bright lights, loud noise, bending of body, following physical exertion etc.

Mongini et al., in (1997) studied 20 patients of chronic daily headache and reported presence of following aggravating factors in their study. Headache was aggravated during weather change in $13(65 \%)$ cases, while performing intellectual activity in $11(55 \%)$ cases, fatigue in $10(50 \%)$ patients, stress in $10(50 \%)$ patients, head movement in $6(30 \%)$ cases, food $4(20 \%)$ patients, sexual intercourse $4(20 \%)$, alcohol in $2(10 \%)$ patients of their study population. ${ }^{19}$

Co-morbidity of psychiatric illness was present in $70.8 \%$ of our chronic migraine headache patients. Similar study reports were shown by various other authors in the past. ${ }^{16,20,21}$

In our study anxiety was found to be common comorbid illness in migraine (35.4\%), followed by Depressive disorder (29.2\%) and Panic disorder (6.2\%). Similar results were reported by Breslau \& Davis and Sandriny et al.22,23

In 1924, FP Moersch published 'Psychiatric manifestation in Migraine' in which he discussed the significance of the depressive and anxiety symptoms in patients with migraine. ${ }^{24}$ In 1993 , Breslau et al., reported that a history of migraine is associated with increased life time of anxiety disorders, substance abuse disorders, nicotine dependence and suicide attempt. ${ }^{25}$

In 1994, Breslau et al., found that the estimated risk of major depression associated with prior migraine was 3.2. The risk for migraine associated with prior depression was 3.1. The bi-directional influences, with each disorder increasing the risk of the other, suggest a shared cause between migraine and depression. ${ }^{25}$

In 1995, Breslau and Andreski reported that migraine was associated with increased incidence of neuroticism, defined as a general emotional overactivity, which may lead to neurotic disorders under stress. ${ }^{26}$

In 1995, Marazziti et al., studied 73 patients suffering from primary headache disorders and reported $41 \%$ psychiatric co-morbidity, with more co-morbidity in migraine with aura group. ${ }^{27}$

Glover and Sandler (1990) studied 40 cases of migraine and suggest that migraine, anxiety, and depression must have a common biochemical basis due to high association in probands as well as in their relatives. ${ }^{28}$

Co-morbidity between migraine and psychiatric disorders has been extensively studied, but the 
mechanisms underlying this phenomenon are far from clear. The evidence from literature points to three main potential mechanisms. ${ }^{29-31}$

1. Psychiatric disorders are causal factors in the development of migraine. In this case, psychiatric disturbances are responsible for a full expression of migraine, and under particular circumstances for the evolution of migraine in a daily pattern (chronic migraine).

2. Migraine is a causal factor in the development of psychiatric disorders. In this case, the repetition of intense and/or long lasting pain episodes may facilitate the development of anticipatory anxiety and/or depression.

3. Shared aetiological factors and common determinants explain the co-occurrence of both entities. In this case, there is no clear causal association, and a common substrate (e.g., deranged activity of neurotransmitters or receptors) may cause both migraine and the co-morbid psychiatric disorder.

With particular regard to the relationship between the frequency of psychiatric co-morbidity and the severity of migraine, some evidence suggested that there is a significant association between frequency and duration of the attacks, but not with the intensity of pain. ${ }^{20}$

A correlation was subsequently observed between the evolution of headache and the presence of anxiety or depression. In this respect, several studies have been focused about onset of specific disorders. In one study anxiety was shown to precede migraine in most patients, which in turn preceded depression. ${ }^{22}$

\section{Conclusion}

There are several reasons for which the study of comorbidity of migraine headache is important. ${ }^{32}$ Migraine is co-morbid with conditions that have similar characteristics to migraine itself. For example, depression and migraine can both produce change in mood and head pain, epilepsy and migraine both produce paroxysmal neurological attacks and both can produce headache as well. At the clinic level, co-morbidity implies the need for high diagnostic vigilance. Comorbidity also has obvious treatment implications. The study of co-morbidities may also provide clues to a common pathophysiology of the disorders.
A high percentage of psychiatric illness comorbidity was found to be present in our chronic migraine headache patients; so a sincere effort should be there to unearth any co-morbid psychiatric illness, for all patients attending for the first time in a 'headache clinic'. A multidisciplinary approach is probably better advocated in dealing with co-morbidity issues in cases of chronic migraine headache patients.

Limitations of the present study, that has been envisaged, are as follows:

1. We enrolled only 48 patients for the present study. Though many study reports are available with lesser number patients, anything above 100 samples would have been better for generalising the findings of the present study.

2. We did not pursue a comparison group with our study group. A "case-control" study would have been a statistically a more robust study design, for accepting and generalising the findings of a study of this nature.

3. Following up these patients for a limited and/or longer period would have gave us more insight into the nature of treatment response to this group of patients with chronic migraine headache, particularly, patients with associated co-morbid psychiatric illness.

\section{REFERENCES:}

1. Lance JW (1998). Mechanism and management of headache. Oxford: BH, 158-175.

2. Rasmussen BK (1995). Epidemiology of headache. Cephalalgia, 15: 45-68.

3. Scher A I, Stewart W F, Lipton R B (1999). Migraine and headache: a meta-analytic approach. In: Crombie I K (ed) Epidemiology of pain. IASP Press, Seattle, $p$ 159170.

4. Stewart WF, Linet MS, et al (1989). Migraine headaches and Panic attacks. Psychosomiatic medicine 51:559-569.

5. International headache society (1991) Classification and diagnostic criteria for headache disorders, cranial neuralgias, and facial pain. Denmark Scandinavian University Press.

6. Headache Classification Committee of the International Headache Society (1988). Classification and diagnostic criteria for headache disorders, cranial neuralgias and facial pain. Cephalalgia 8 (suppl 7):1-96.

7. Headache Classification Subcommittee of the International Headache Society (2004). The International Classification of Headache Disorders, 2nd edition. Cephalalgia 24(suppl 1):9-160.

8. Olesen J, Goadsby P J, Ramadan NM.; Tfelt-Hansen P, Welch K, Michael A (2006). The Headaches (3rd ed.). 
Philadelphia, Pennsylvania, USA: Lippincott Williams E Wilkins. pp. 1-13

9. Silberstein SD, Lipton RB, Sliwinski M (1996). Classification of daily and near daily headaches: field trial of revised IHS criteria. Neurology 47:871-875.

10. Lipton RB (1998). Co-morbidity in migraine cause and effects. Cephalgia 18 (Supplement 22):8-14.

11. SCAN Schedules for clinical Assessment in Neuropsychiatry, version 2.1:WHO (1996).

12. World Health Organization (1992). The ICD-10 classification of mental and behavioural disorders: clinical descriptions and diagnostic guidelines. World Health Organization, Geneva.

13. Hamilton M (1959). The assessment of anxiety states by rating. Br J Med Psychol 1959; 32:50-55.

14. Hamilton, $M$ (1960) A rating scale for depression. Journal of Neurology, Neurosurgery and Psychiatry. 23: 56-62

15. Mitsikostas DD, Thomas AM 1999 Co-morbidity of headache and depressive disorders. Cephalgia 19:211217.

16. Juang MD, Wang SJ, Fuh JL, Shiang RL, Tung PS, 2000 Comorbidity of depressive and anxiety disorders in chronic headache and its subtypes. The Journal of Head and Face Pain 40:818-823.

17. Mercente et al (2005). Depression in Chronic Migraine. Arq Neuropsiquiatr, 63(2-A):217-220.

18. Wang et al., (2009) Chronic daily headache in adolescents an 8 year follow up study, Neurology 73:416421.

19. Franco Mongini MD, Nadia Defilippi DDS and Cesare Negro (1997) Chronic Daily Headache. A Clinical and Psychological Profile Before and After Treatment. Headache: The Journal of Head and Face Pain 37: 83-87.

20. Verri AP, Sndrini G,Nappi G, et al (1998). Psychiatric co-morbidity in chronic daily headache. Cephalgia 18 (supplement 21), 45-49.

21. Khess CRJ, Akhtar S, Kumar R, Basu S (1999). Headache and depression. The mind healer 2:16-19.

22. Breslau N, Davis GC (1993). Migraine, Psysical health and psychiatric disorder: a prospective epidemiologic study in young adults. Journals of Psychiatric research 27:211 221.

23. Sandrini G, Verri AP, Barbieri E, et al (1995). Psychiatric co-morbidity in chronic daily headache. Cephalgia 15(supplement14) 163-167.

24. Moersch FP (1924). Psychic manifestations in migraine. American journals of Psychiatry 3:698-

25. Breslau N, Davis GC, Schultz LR (1994). Migraine and major depression: a longitudinal study. Headache 34:387-393.

26. Breslau N, Andreski P (1995). Migraine, personality, and psychiatric co morbidity. Headache 35:382-386.

27. Marazziti D, Toni C, Pedri S, et al. (1995). Headache, panic disorder and depression: co-morbidity or a spectrum. Nero psychobiology 31:125-129.
28. Glover V, Sandler M 1990 The biochemical basis of migraine predisposition. In: Sandler $M$, Collins GM(eds): Migraine: A spectrum of ideas. New York, Oxford University Press 228-247.

29. Radat F, Swendsen J 2005 Psychiatric co-morbidity in migraine: a review. Cephalalgia 25:165-178.]

30. McWilliams LA, Goodwin RD, Cox BJ (2004) Depression and anxiety associated with three pain conditions: results from a nationally representative sample. Pain 111:77-83.

31.Lipton RB, Silberstein SD 1994 Why study the co morbidity of migraine? Neurology 44 (supplement 7):45.

32. Lipton RB, Silberstein SD (1994) Why study the co morbidity of migraine? Neurology 44 (supplement 7):45. 